\title{
Low Frequency Filter Design using Operational Transconductance Amplifier
}

\author{
Dr Rajeshwari S Mathad \\ Department of Electronics, Basaveshwar Science College,BAGALKOT
}

\begin{abstract}
Biomedical signal processing requires low power consumption and low frequency filters. Biomedical signals are usually of $10-\mathrm{mHz}$ to $100-\mathrm{Hz}$ and maximum of $500 \mathrm{~Hz}$ frequency range. The equipments used in the design of biomedical applications require portability and circuit needs to be operated with low supply voltage. These requirements can be fulfilled by using active filters designed by Operational Transconductance Amplifier.
\end{abstract}

Keywords: Operational Transconductance Amplifier (OTA), OTA-C, Operational Transconductance Amplifier - Capacitor.

\section{INTRODUCTION}

Integrated circuit technologies for biomedical applications have been widely used in recent years. The instruments used in biomedical applications may be having some restrictions on battery charges for all portable electronic devices. To satisfy with ambulatory functions the circuit should not only with low power but also with low voltage. Therefore in this paper a low power- low voltage Operational Transconductance Amplifier (OTA) is used to design a low frequency active low pass filter, thus component count can be drastically reduced. The circuit can be operated with low supply voltage of order $1.8 \mathrm{~V}$, high stability and linearity in the response, with high signal to noise ratio can be obtained. The required cut off frequency can be tuned electronically. All these requirements cannot be fulfilled in the filter design using operational amplifier. In active filter design using operational amplifier, electronic tuning is not possible. To change the value of cut off frequency calculations has to be done to change values of resistance and capacitance. Portability cannot be obtained in active filters using operational amplifiers because the component count is more in comparison with OTA active filters [1]-[3].

The time constant of operational transconductance amplifier-capacitor (OTA-C) filter is determine by the ratio of load capacitor to the OTA transconductance, i.e $\mathrm{C} / \mathrm{g}_{\mathrm{m}}$. For an OTA-C filter implementation in low frequency implies large capacitance and very low transconductance [4]-[5]. Thus there are two different techniques to solve this problem. One is to design an OTA with very low transconductance and another is to realize filter with large load capacitance. In this paper, current division technique is used to obtain a low transconductance, for implementation of very large time constant. Using this technique an OTA-C active filter can be designed for low frequency applications.

In this paper, a low frequency Active filter design using OTA has been explained. The total number of components used in these circuits are very small, the design equations and voltage- current characteristics are attractive. An improvement in design simplicity is observed in comparison with op amp based structures. An OTA is a voltage controlled current source, more specifically the term "operational" comes from the fact that it takes the difference of two voltages at the input, and converts it into output current.

The ideal transfer characteristic of OTA is $\mathrm{Io}=\mathrm{g}_{\mathbf{m}}\left(\mathrm{V1}^{+}-\mathrm{V} 2^{-}\right)$

Where $\mathrm{V}^{+}-\mathrm{V} 2^{-}$is a differential input voltage and Io is a output current and $\mathbf{g}_{\mathrm{m}}$ is the transconductance gain of OTA.

By taking the pre-computed difference as the input, Io $=\mathbf{g}_{\mathrm{m}}$ Vin

The transconductances $\mathbf{g}_{\mathbf{m}}$ is also a function of the input differential voltage. The term "transconductance" in OTA is the ratio of output current to the input voltage, $\mathbf{g}_{\mathbf{m}}$, has the unit of conductance. 


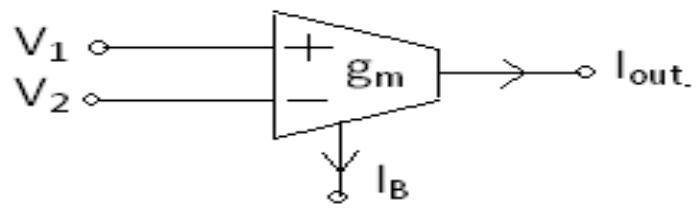

Figure 1. Circuit symbol of OTA

\section{PRINCIPLE OF OPERATION AND CIRCUIT ANALYSIS}

OTA-based filters are composed of the open-loop OTA-C integrators in which the devices are operated in the subthreshold region to realize a very low transconductances, typically of the order of a few nano amperes. In OTA-based circuits, the bias current will dominate the performance of the filter circuit, and the ratio of capacitance to small transconductance determines the time constant of OTA-C integrators [4].

An active RC filter can be designed using OTA as a variable resistance simulator. Variable resistors are one of the applications of OTA. There are two types of OTA variable resistance simulators, those are positive resistance simulator and negative resistance simulator, depending on their feedback polarities. "Fig 2" and "Fig 3" shows two positive resistance simulators, realized using negative feedback. The input impedance of these two versions can be derived by assuming an input voltage $v_{i}$ and an input current $i_{i}$ for each version.

$\mathrm{Z}_{\mathrm{i}}=\mathrm{v}_{\mathrm{i}} / \mathrm{i}_{\mathrm{i}}=1 / \mathbf{g}_{\mathrm{m}}$

OTA is assumed to have a transconductance $\mathbf{g}_{\mathbf{m}}$. At frequencies much lower than the cut off frequency of the OTAs, $\mathbf{g}_{\mathbf{m}}$ is real, thus $\mathrm{Z}_{\mathrm{i}}$ becomes a resistor using single OTA and two OTAs. Resistance values are realized by varying the bias current of the OTA. OTA variable resistors with capacitors can compose OTA-C filters, where these OTA variable resistors are used to tune the filter frequencies.

The performance of the proposed circuit is illustrated by Proteus Proffessional-7.5 simulations, which are in accordance with theoretical predictions. In this paper for experimental work OTA LM13600 is used.

The transconductances $\mathbf{g}_{\mathbf{m}}$ is given by, $\mathbf{g}_{\mathbf{m}}=\mathrm{I}_{\text {bias }} / 2 \mathrm{~V}_{\mathrm{T}}$

Where $\mathrm{V}_{\mathrm{T}}$ : thermal voltage $=26 \mathrm{mV}$ at room temperature, $\mathrm{I}_{\text {bias }}$ : bias current.

The proposed circuit of the floating positive resistance simulator is shown in "Fig. 2", where $\mathrm{I}_{\mathrm{b}}$ is the bias current of the OTA.

\subsection{Simulation of positive floating resistance using single OTA}

Consider the circuit in "Fig. 2" it is a positive resistance simulator using single OTA. By properties of the OTA, we will get,

$\mathrm{R}_{\mathrm{eq}}=\operatorname{Vin}^{+}-\mathrm{Vin}^{-} / \mathrm{I}_{\mathrm{R}}=1 / \mathbf{g}_{\mathbf{m}}$

Where $\quad \mathbf{g}_{\mathbf{m}}=\mathrm{I}_{\text {bias }} / 2 \mathrm{~V}_{\mathrm{T}}$

Therefore, $\quad \mathrm{R}_{\mathrm{eq}}=2 \mathrm{~V}_{\mathrm{T}} / \mathrm{I}_{\text {bias }}$.

From above equation it is clear that resistance value can be easily electronically varied by varying the bias current.

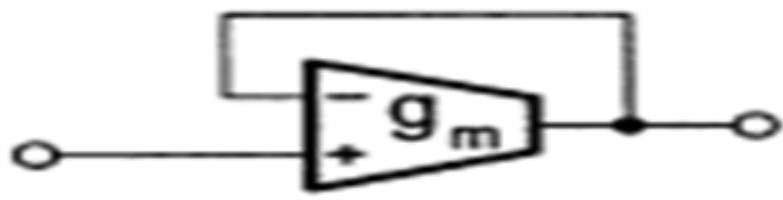

Figure 2 OTA simulation of floating resistor

\subsection{Simulation of positive floating resistance using two OTAs.}

Consider the circuit shown in "Fig. 3", it is a positive resistance simulator using two OTAs. The bias current applied for two OTAs is $I_{B}$ (refer in "Fig. 6"). This externally applied bias current $I_{B}$ divides between two OTAs. For each OTA bias current $\mathrm{I}_{\mathrm{b}}=\mathrm{I}_{\mathrm{B}} / 2$. Therefore the transconductance $\mathrm{g}_{\mathrm{m}}$ for two OTAs is given by, $\mathrm{g}_{\mathrm{m}}=\mathrm{g}_{\mathrm{m}}$. The current division concept used in this circuit is mainly useful to obtain lower value of 
transconductances, which helps in the design of active filters in low frequency range to obtain larger value of time constant. The simulated resistance which depends on bias current is reciprocal transconductances $\mathrm{g}_{\mathrm{m}}$.

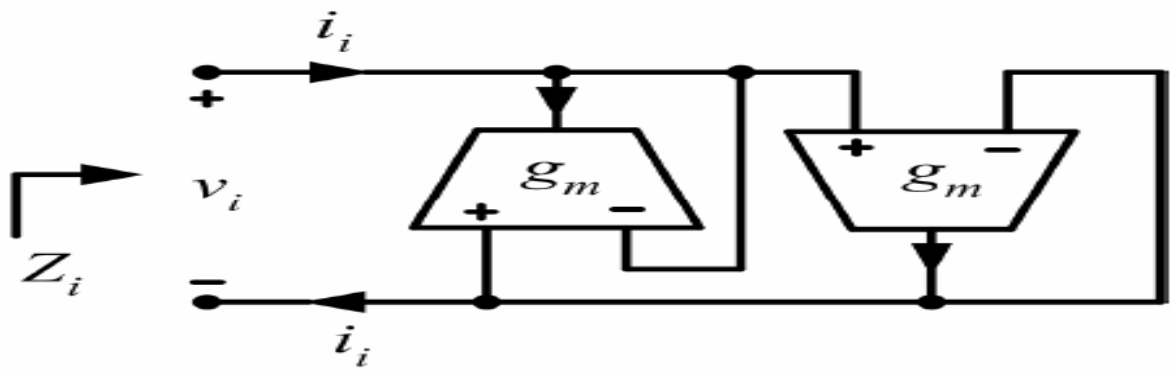

Figure 3 Simulation of floating resistor using two OTAs

\subsection{Low frequency RC low pass filter using OTA}

A low frequency RC low pass filter is designed using OTA resistance simulator. Both type of resistance simulators are used in filter design, i,e using single OTA and using two OTAs. "Fig 4" shows the conventional circuit of RC low pass filter. "Fig 5" is a RC low pass filter using single OTA and "Fig 6" is a RC low pass filter using two OTAs. Output of the filter is measured by varying the bias current to obtain required cut off frequency.[1]-[6]

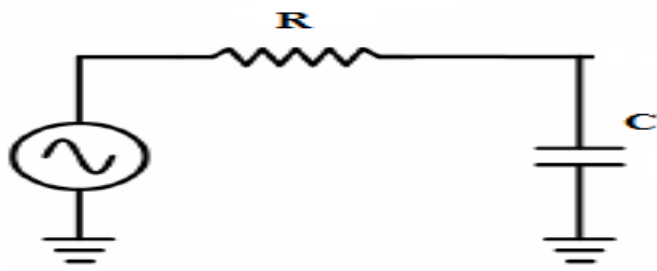

Figure 4 Conventional circuit of RC low pass filter.

III. EXPERIMENTAL SETUP

The stated circuits of "Fig 5" and "Fig 6" are simulated using Proteus professional 7.5 software. Same circuits are arranged on bread board using an OTA LM13600 to verify the software results. Output of the filter is observed by varying the bias current of OTAs.

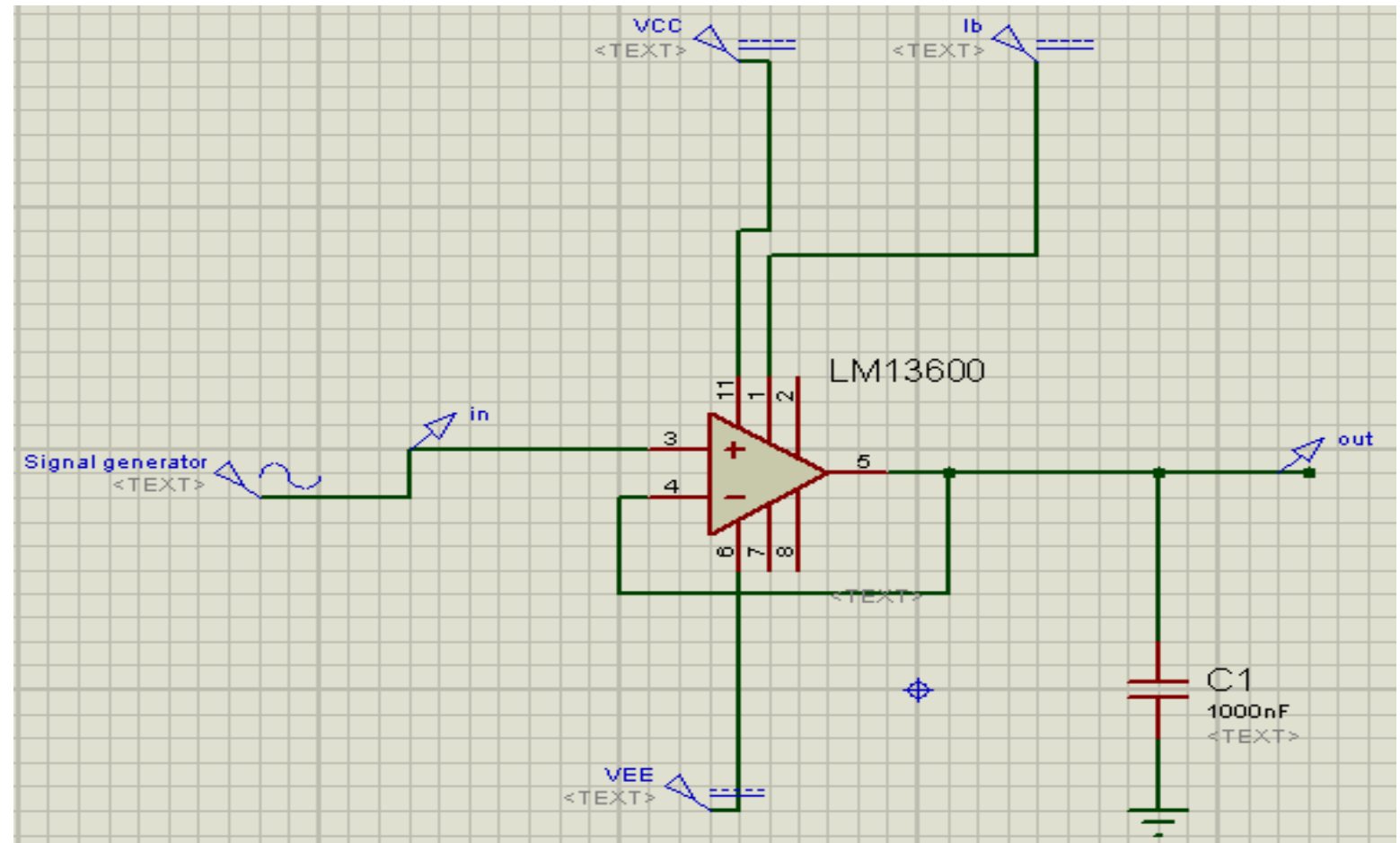

Figure. 5 Circuit diagram of OTA- C Low Pass filter using software 


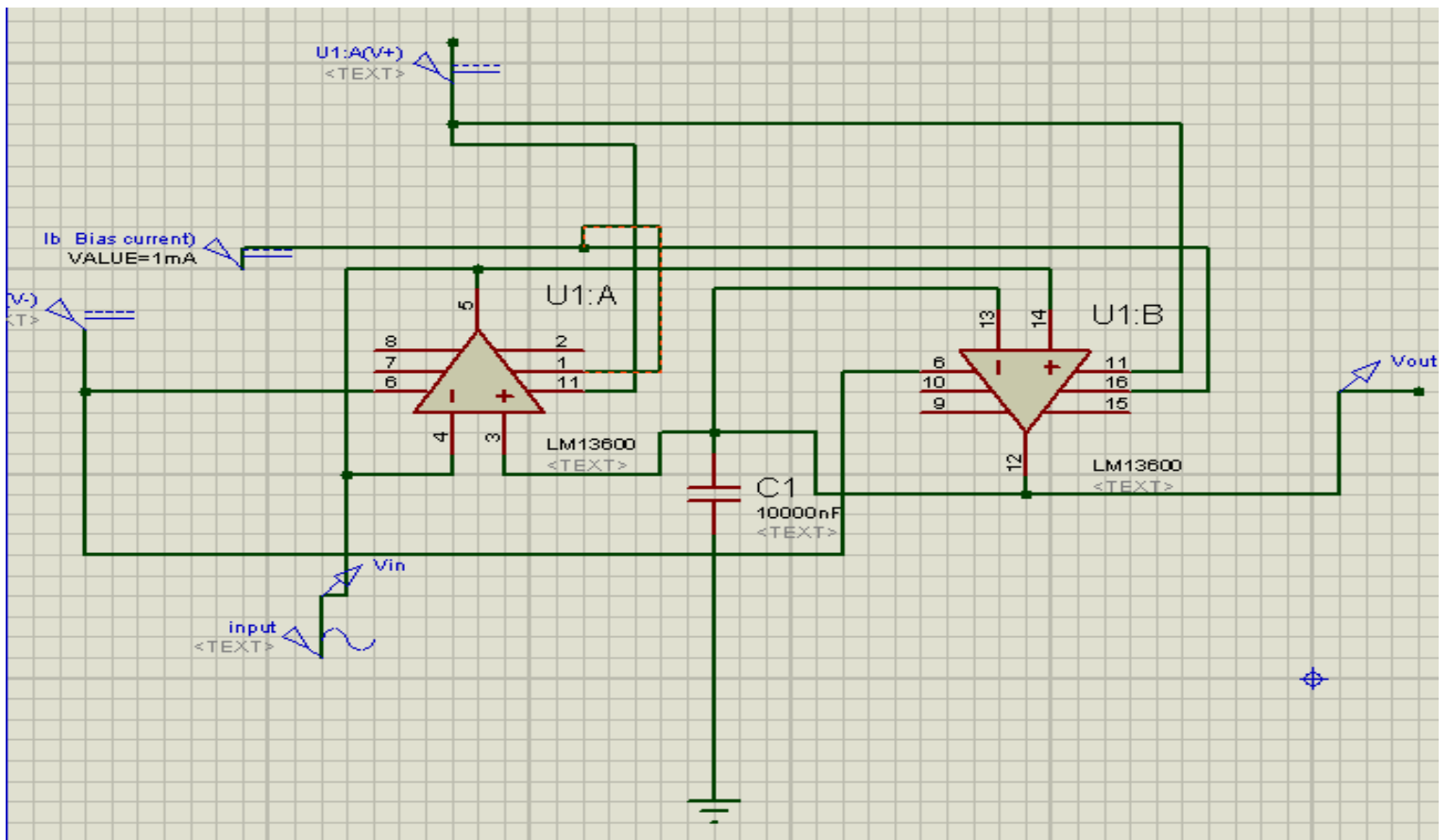

Figure. 6 Circuit diagram of Low Pass filter using two OTAs.

\section{RESULTS AND DISCUSSION}

The studied circuits using single OTA and two OTAs function as low pass filter. Output of the filter is obtained by varying the bias current of OTA for two different values of output capacitive load i,e $\mathrm{C}=10 \mu \mathrm{F}$ and $100 \mu \mathrm{F}$. Software results are verified by theoretical calculations and also they are confirmed by connecting the circuit on breadboard and practical results validates with software results.

\subsubsection{Low frequency RC low pass filter using single OTA}

The circuit shown in "Fig 5" is an active RC low pass filter in which the series resistance connected in $\mathrm{RC}$ active filter is a OTA resistance simulator.The resistance simulator used, in this filter circuit is a positive resistance simulator, ( ref Fig 2) because the output terminal is connected to negative input terminal to obtain positive resistance simulation. By mere changing $\mathrm{I}_{\text {bias }}$ from $100 \mathrm{nA}$ to $2 \mathrm{~mA}$, the simulated value of resistance obtained is from $\mathbf{5 2 0 K} \Omega$ to $26 \Omega$ i.e Hundreds of Kilo ohms to ohms. Simulated resistance behaves like a passive resistor of positive temperature coefficient.

Proposed circuit of active RC low pass filter comprises only single OTA and a capacitor C. Resistance values are realized by varying the bias current of the OTA. The resistance values simulated by OTA for different bias currents are given in table 1.1. By using single OTA resistance simulator, an active RC low pass filter is designed which is shown in "Fig 5.". The cut off frequencies of this OTA-C RC low pass filter are obtained by varying the bias current from 100nA to $2 \mathrm{~mA}$, by using Proteus professional 7.5 software. These cut off frequencies are verified with calculated values of cut off frequencies of an active RC low pass filter. These results are tabulated in tables 1.1 and 1.2.

Table 1.1

\begin{tabular}{|c|c|c|c|}
\hline \multicolumn{4}{|c|}{$\mathrm{C}=10 \mu \mathrm{F}$} \\
\hline $\begin{array}{c}\text { Bias current } \\
\mathbf{I}_{\text {bias }}\end{array}$ & $\begin{array}{c}\text { Software results } \\
\mathbf{f}_{-3 \mathrm{~dB}}\end{array}$ & $\begin{array}{c}\text { Simulate } \\
\text { Resistance } \\
\mathbf{R}=1 / \mathbf{g}_{\mathrm{m}}\end{array}$ & $\begin{array}{l}f_{-3 d B}=\underset{2 \pi}{g_{m}} \\
=1 / 2 \pi R C\end{array}$ \\
\hline $100 n A$ & $30.9 \mathrm{mHz}$ & $520 \mathrm{~K} \Omega$ & $30.06 \mathrm{mHz}$ \\
\hline 500nA & $152 \mathrm{mHz}$ & $104 \mathrm{~K} \Omega$ & $153 \mathrm{mHz}$ \\
\hline $1 \mu \mathrm{A}$ & $301 \mathrm{mHz}$ & $52 \mathrm{~K} \Omega$ & $306 \mathrm{mHz}$ \\
\hline $10 \mu \mathrm{A}$ & $3.13 \mathrm{~Hz}$ & $5.2 \mathrm{~K} \Omega$ & $3.06 \mathrm{~Hz}$ \\
\hline $100 \mu \mathrm{A}$ & $31.7 \mathrm{~Hz}$ & $520 \Omega$ & $30.6 \mathrm{~Hz}$ \\
\hline $500 \mu \mathrm{A}$ & $154 \mathrm{~Hz}$ & $104 \Omega$ & $153 \mathrm{~Hz}$ \\
\hline $1 \mathrm{~mA}$ & $303 \mathrm{~Hz}$ & $52 \Omega$ & $306 \mathrm{~Hz}$ \\
\hline $2 \mathrm{~mA}$ & $600 \mathrm{~Hz}$ & $26 \Omega$ & $612 \mathrm{~Hz}$ \\
\hline
\end{tabular}


From table 1.1 it is clear that, by varying the bias current from $100 \mathrm{nA}$ to $2 \mathrm{~mA}$ the cut off frequencies obtained are from $30.9 \mathrm{mHz}$ to $600 \mathrm{~Hz}$, for $\mathrm{C}=10 \mu \mathrm{F}$. Theoretical cut off frequencies validates with software results.

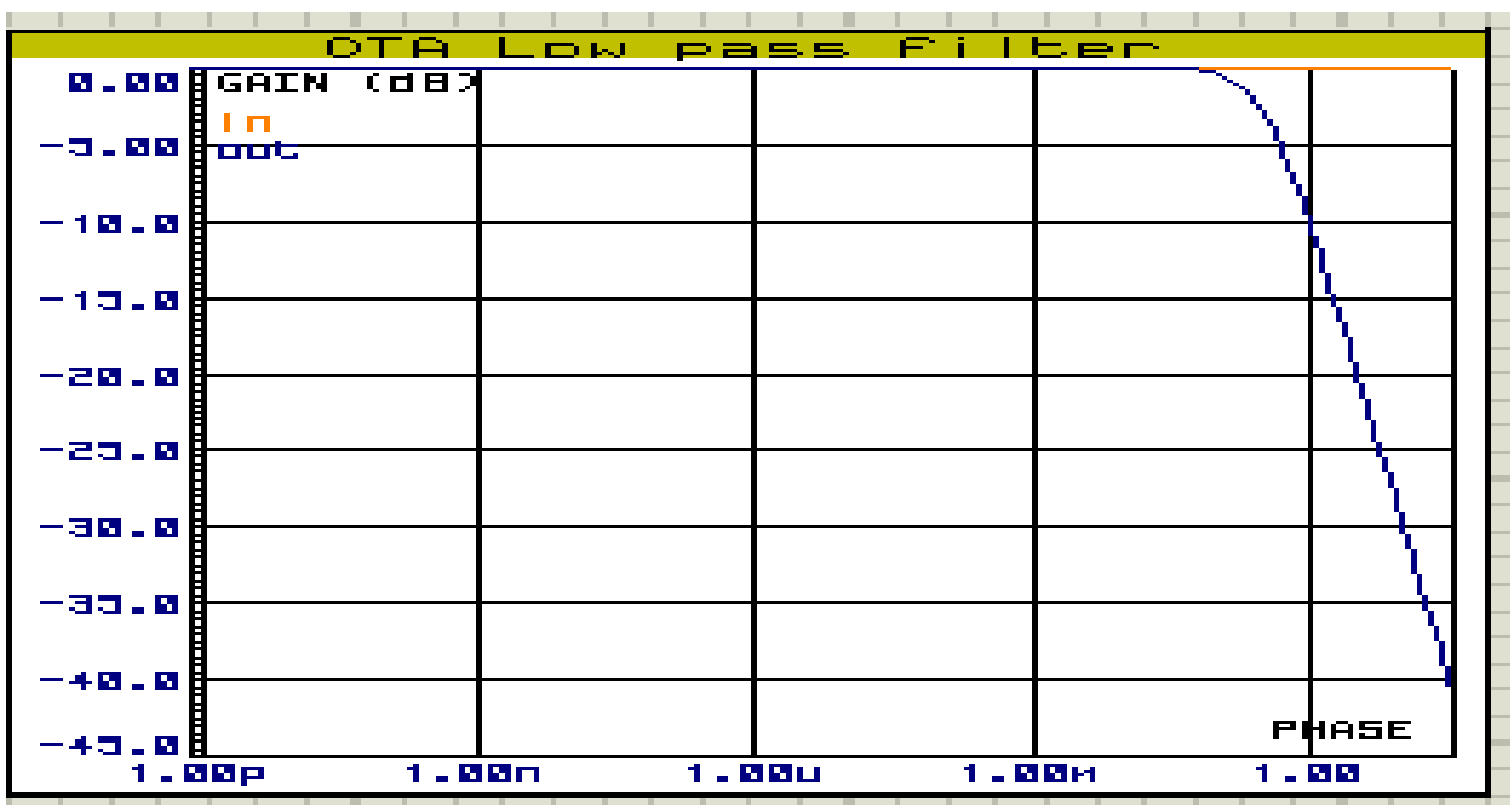

Figure.7 Frequency response of Proteus professional 7.5 simulated OTA-C low pass filter, for $\mathrm{C}=10 \mu \mathrm{F}$ with $I_{\text {bias }}=1 \mu \mathrm{A}$, with maximum. gain $0 \mathrm{~dB}$ and cut off frequency of $301 \mathrm{mHz}$ at $-3 \mathrm{~dB}$.

Table 1.2

\begin{tabular}{|cccc|}
\hline $\begin{array}{c}\text { Bias current } \\
\mathbf{I}_{\text {bias }}\end{array}$ & $\begin{array}{c}\text { Software results } \\
\mathbf{f}_{-3 \mathrm{~dB}}\end{array}$ & $\begin{array}{c}\text { Simulate } \\
\text { Resistance } \\
\mathbf{R}=\mathbf{1} / \mathbf{g}_{\mathbf{m}}\end{array}$ & $\begin{array}{r}\mathbf{f}_{-\mathbf{3 d B}}=\mathbf{\mathbf { g } _ { \mathbf { m } }} \\
\mathbf{2} \boldsymbol{\pi} \mathbf{C} \\
\mathbf{= 1 / 2} \mathbf{R} \mathbf{R}\end{array}$ \\
\hline $\mathbf{1 0 0 n A}$ & $3.09 \mathrm{mHz}$ & $520 \mathrm{~K} \Omega$ & $3.06 \mathrm{mHz}$ \\
\hline $\mathbf{5 0 0 n A}$ & $15.3 \mathrm{mHz}$ & $104 \mathrm{~K} \Omega$ & $15.3 \mathrm{mHz}$ \\
\hline $\mathbf{1} \boldsymbol{\mu A}$ & $30.1 \mathrm{mHz}$ & $52 \mathrm{~K} \Omega$ & $30.6 \mathrm{mHz}$ \\
\hline $\mathbf{1 0} \boldsymbol{\mu} \mathbf{A}$ & $209 \mathrm{mHz}$ & $5.2 \mathrm{~K} \Omega$ & $306 \mathrm{mHz}$ \\
\hline $\mathbf{1 0 0} \boldsymbol{\mu} \mathbf{A}$ & $3.13 \mathrm{~Hz}$ & $520 \Omega$ & $3.06 \mathrm{~Hz}$ \\
\hline $\mathbf{5 0 0} \boldsymbol{\mu} \mathbf{A}$ & $15.2 \mathrm{~Hz}$ & $104 \Omega$ & $15.30 \mathrm{~Hz}$ \\
\hline $\mathbf{1 m A}$ & $30 \mathrm{~Hz}$ & $52 \Omega$ & $30.60 \mathrm{~Hz}$ \\
\hline $\mathbf{2 m A}$ & $60 \mathrm{~Hz}$ & $26 \Omega$ & $61.21 \mathrm{~Hz}$ \\
\hline
\end{tabular}

From table 1.2 by varying the bias current from $100 \mathrm{nA}$ to $2 \mathrm{~mA}$ the cut off frequencies obtained are from $3.09 \mathrm{mHz}$ to $60 \mathrm{~Hz}$, for $\mathrm{C}=100 \mu \mathrm{F}$.

As capacitance value $\mathrm{C}$ is further increased, for given bias currents from $100 \mathrm{nA}$ to $2 \mathrm{~mA}$ the cut off frequencies can be still further decreased. 


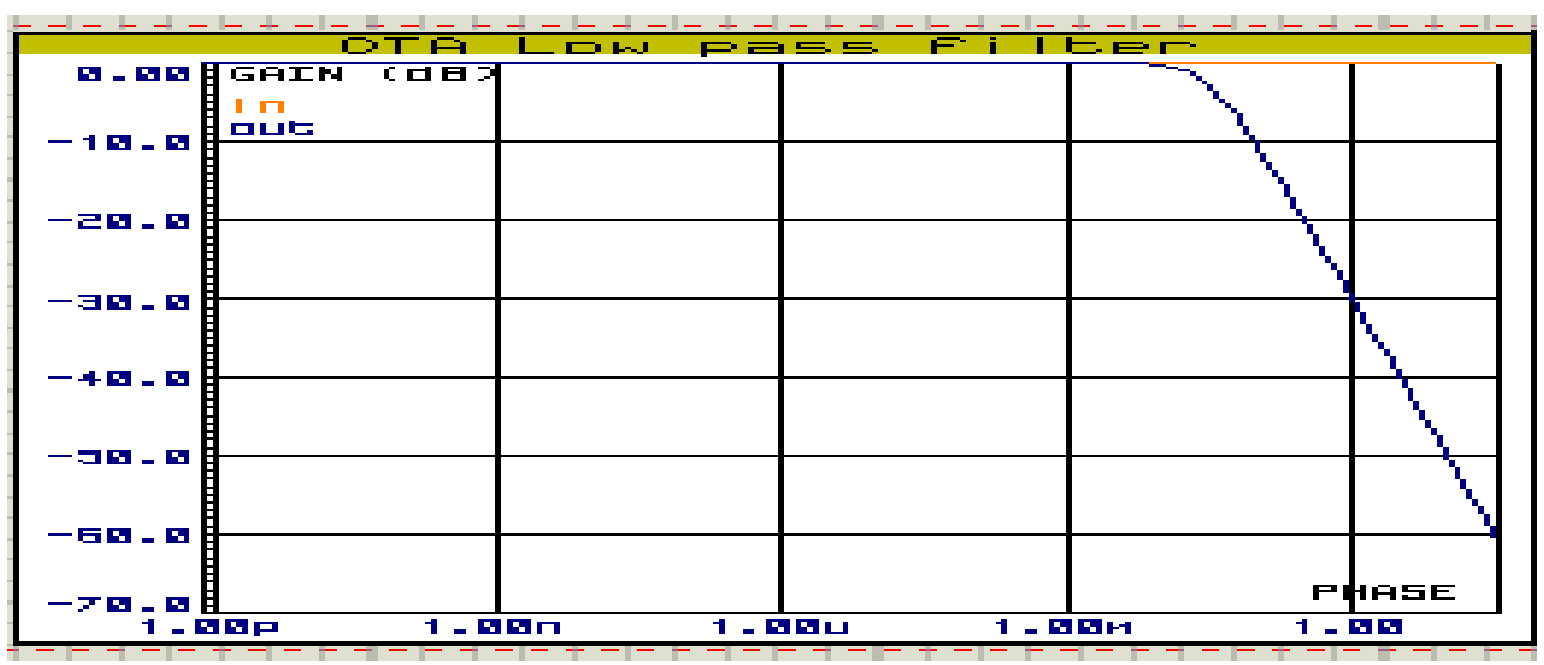

Figure.8 Frequency response of Proteus professional 7.5 simulated OTA-C low pass filter , for $\mathrm{C}=100 \mu \mathrm{F}$ with $\mathrm{I}_{\text {bias }}=1 \mu \mathrm{A}$, with maximum gain $0 \mathrm{~dB}$ and cut off frequency of $30.1 \mathrm{mHz}$ at $-3 \mathrm{~dB}$.

\subsubsection{Low frequency RC low pass filter using two OTAs.}

The circuit shown in Figure 6 is an active RC low pass filter in which the series resistance connected in $\mathrm{RC}$ active filter is a OTA resistance simulator using two OTAs. The resistance simulator used, in this filter circuit is a positive resistance simulator,( ref Fig 3) because the output terminal is connected to negative input terminal to obtain positive resistance simulation. In this type of resistance simulation the transconductance of two OTAs are given by $\mathrm{g}_{\mathrm{m}}=\mathrm{g}_{\mathrm{m}}$, therefore $\mathrm{R}=1 / \mathrm{g}_{\mathrm{m}}$. In case of bias current, current division takes place. It means $\mathrm{I}_{\text {bias }}$ equally divides between two OTAs. For example if $\mathrm{I}_{\mathrm{B}}=100 \mu \mathrm{A}$ then bias current of each OTA will be $50 \mu \mathrm{A}$, and $\mathrm{g}_{\mathrm{m}}=\mathrm{I}_{\text {bias }} / 2 \mathrm{~V}_{\mathrm{T}}=50 \mu \mathrm{A} / 2 \times 26 \mathrm{mV}$.

By mere changing $\mathrm{I}_{\text {bias }}$ from $100 \mathrm{nA}$ to $4 \mathrm{~mA}$, it means $50 \mathrm{nA}$ to $2 \mathrm{~mA}$ for each OTA, the simulated value of resistance obtained is from $1040 \mathrm{~K} \Omega$ to $26 \Omega$ i.e Thousands of Kilo ohms to ohms . Therefore the advantage of this circuit is that, we can obtain $1 \mathrm{G} \Omega$ of resistance. Such a high resistance gives larger time constant, which is useful in filter designing.

Proposed circuit of active RC low pass filter comprises of two OTAs and a capacitor C. Resistance values are realized by varying the bias current of the OTA. The resistance values simulated by OTAs for different bias currents are given in table 1.3. By using this, two OTAs resistance simulator an active RC low pass filter is designed which is shown in Figure 6. Cut off frequencies of OTA-C RC low pass filter are obtained by varying the bias current from $100 \mathrm{nA}$ to $4 \mathrm{~mA}$, by using Proteus professional 7.5 software. These cut off frequencies are verified with calculated value of cut off frequencies of an active RC low pass filter. These results are tabulated in tables 1.3 and 1.4 .

\section{Table 1.3}

\begin{tabular}{|c|c|c|c|c|}
\hline \multicolumn{5}{|c|}{$C=10 \mu \mathrm{F}$} \\
\hline $\begin{array}{c}\text { Bias current } \\
\mathbf{I}_{\mathbf{B}}\end{array}$ & $\begin{array}{l}\text { For each OTA } \\
\qquad \begin{array}{c}\mathrm{I}_{\mathrm{b} 1}=\mathrm{I}_{\mathrm{b} 2} \\
=\mathrm{I}_{\mathrm{B}} / 2\end{array}\end{array}$ & $\begin{array}{l}\text { Simulate } \\
\text { Resistance } \\
\mathrm{R}=1 / \mathbf{g}_{\mathbf{m}}\end{array}$ & $\begin{array}{l}\text { Calculated cut off frequency } \\
\qquad \begin{array}{c}f_{-3 \mathrm{~dB}}=\underset{g_{\mathrm{m}}}{2 \pi \mathrm{C}} \\
=1 / 2 \pi \mathrm{RC}\end{array}\end{array}$ & $\begin{array}{c}\text { Software results } \\
\mathbf{f}_{-3 \mathrm{~dB}}\end{array}$ \\
\hline $100 n A$ & $50 \mathrm{nA}$ & $1040 \mathrm{~K} \Omega$ & $15.2 \mathrm{mHz}$ & $15.8 \mathrm{mHz}$ \\
\hline $500 n A$ & $250 \mathrm{nA}$ & $208 \mathrm{~K} \Omega$ & $7.63 \mathrm{mHz}$ & $7.83 \mathrm{mHz}$ \\
\hline $1 \mu \mathrm{A}$ & $500 \mathrm{nA}$ & $104 \mathrm{~K} \Omega$ & $15.2 \mathrm{mHz}$ & $158 \mathrm{mHz}$ \\
\hline $10 \mu \mathrm{A}$ & $5 \mu \mathrm{A}$ & $10.04 \mathrm{~K} \Omega$ & $1.52 \mathrm{~Hz}$ & $1.58 \mathrm{~Hz}$ \\
\hline $100 \mu \mathrm{A}$ & $50 \mu \mathrm{A}$ & $1 \mathrm{~K} \Omega$ & $15.3 \mathrm{~Hz}$ & $15.7 \mathrm{~Hz}$ \\
\hline $500 \mu \mathrm{A}$ & $250 \mu \mathrm{A}$ & $208 \Omega$ & $76.4 \mathrm{~Hz}$ & $77 \mathrm{~Hz}$ \\
\hline $1 m A$ & $500 \mu \mathrm{A}$ & $104 \Omega$ & $152.9 \mathrm{~Hz}$ & $152 \mathrm{~Hz}$ \\
\hline $2 \mathrm{~mA}$ & $1 \mathrm{~mA}$ & $52 \Omega$ & $306 \mathrm{~Hz}$ & $299 \mathrm{~Hz}$ \\
\hline $3 \mathbf{m A}$ & $1.5 \mathrm{~mA}$ & $34.7 \Omega$ & $458 \mathrm{~Hz}$ & $450 \mathrm{~Hz}$ \\
\hline $4 \mathrm{~mA}$ & $2 \mathrm{~mA}$ & $26 \Omega$ & $612 \mathrm{~Hz}$ & $600 \mathrm{~Hz}$ \\
\hline
\end{tabular}




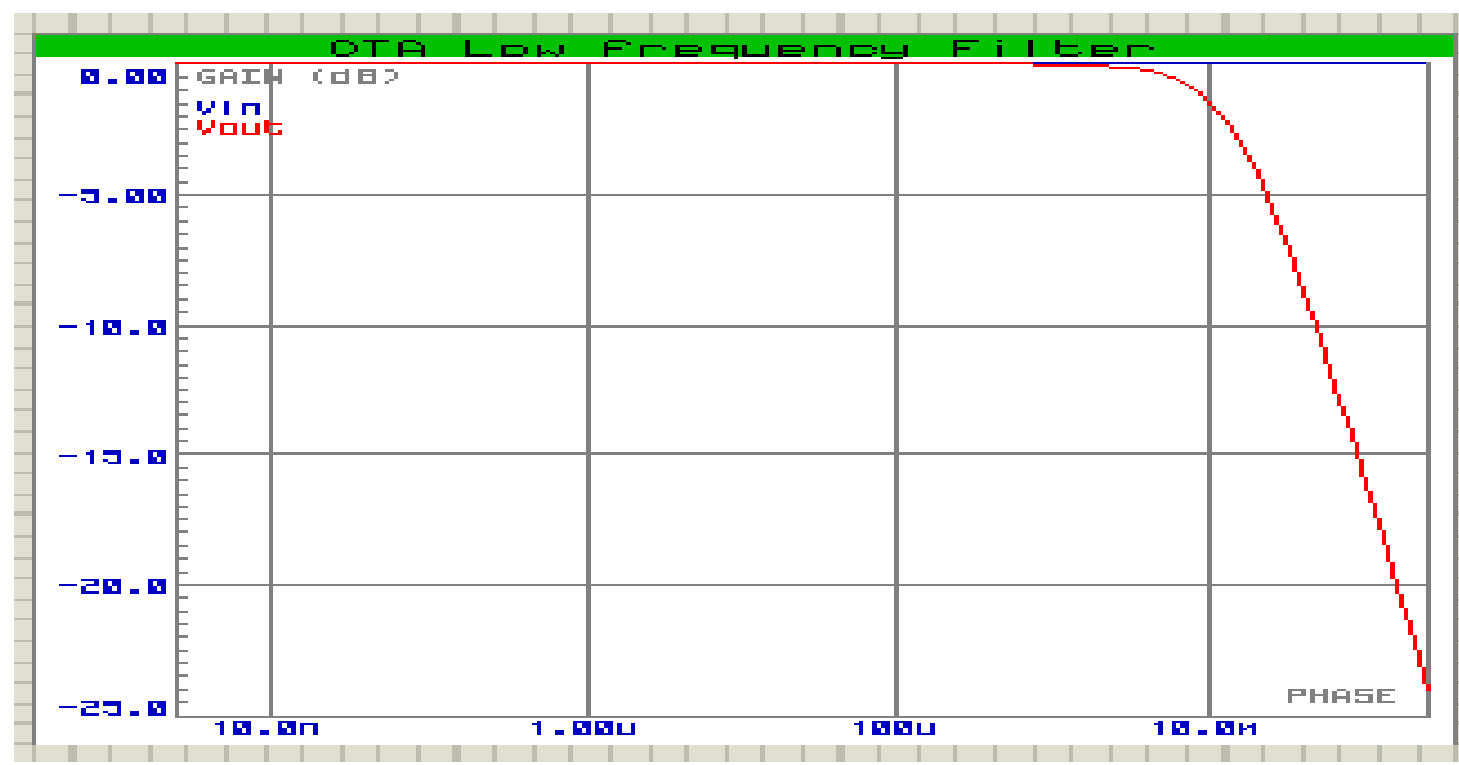

Figure.9 Frequency response of Proteus professional 7.5 simulated OTA-C low pass filter circuit, for $\mathrm{C}=10 \mu \mathrm{F}$ with $\mathrm{I}_{\text {bias }}=100 \mathrm{nA}$, with maximum gain $0 \mathrm{~dB}$ and cut off frequency of $15.2 \mathrm{mHz}$ at $-3 \mathrm{~dB}$.

From table 1.3 it is clear that, by varying the bias current from $100 \mathrm{nA}$ to $4 \mathrm{~mA}$, ( but for each OTA bias current $I_{B}$ is taken as $I_{b 1}=I_{b 2}=I_{B} / 2$, therefore variation of bias current is considered to be from $50 \mathrm{nA}$ to $2 \mathrm{~mA}$ ) the cut off frequencies obtained are from $15.2 \mathrm{mHz}$ to $612 \mathrm{~Hz}$, for $\mathrm{C}=10 \mu \mathrm{F}$.

Table 1.4

\begin{tabular}{|c|c|c|c|c|}
\hline \multicolumn{5}{|c|}{$\mathrm{C}=100 \mu \mathrm{F}$} \\
\hline $\begin{array}{c}\text { Bias current } \\
\text { Ib }\end{array}$ & $\begin{array}{l}\text { For each OTA } \\
\begin{array}{c}\mathrm{Ib} 1=\mathrm{Ib} 2 \\
=\mathrm{Ib} / 2\end{array}\end{array}$ & $\begin{array}{c}\text { Simulate } \\
\text { Resistance } \\
\mathrm{R}=1 / \mathbf{g}_{\mathbf{m}}\end{array}$ & $\begin{array}{l}\text { Calculated cut off frequency } \\
\qquad \begin{array}{c}f_{-3 \mathrm{~dB}}=\mathrm{g}_{\mathrm{m}} \\
2 \pi \mathrm{C} \\
=1 / 2 \pi \mathrm{RC}\end{array}\end{array}$ & $\begin{array}{c}\text { Software } \\
\text { results } \\
\mathbf{f}_{-3 \mathrm{~dB}}\end{array}$ \\
\hline $100 n A$ & $50 \mathrm{nA}$ & $1040 \mathrm{~K} \Omega$ & $1.52 \mathrm{mHz}$ & $1.57 \mathrm{mHz}$ \\
\hline $500 n A$ & $250 \mathrm{nA}$ & $208 \mathrm{~K} \Omega$ & $7.63 \mathrm{mHz}$ & $7.86 \mathrm{mHz}$ \\
\hline $1 \mu \mathbf{A}$ & $500 \mathrm{nA}$ & $104 \mathrm{~K} \Omega$ & $15.2 \mathrm{mHz}$ & $15.6 \mathrm{mHz}$ \\
\hline $10 \mu \mathrm{A}$ & $5 \mu \mathrm{A}$ & $10.04 \mathrm{~K} \Omega$ & $152 \mathrm{mHz}$ & $158 \mathrm{mHz}$ \\
\hline $100 \mu \mathrm{A}$ & $50 \mu \mathrm{A}$ & $1 \mathrm{~K} \Omega$ & $1.53 \mathrm{~Hz}$ & $1.57 \mathrm{~Hz}$ \\
\hline $500 \mu \mathrm{A}$ & $250 \mu \mathrm{A}$ & $208 \Omega$ & $7.63 \mathrm{~Hz}$ & $7.68 \mathrm{~Hz}$ \\
\hline $\operatorname{lmA}$ & $500 \mu \mathrm{A}$ & $104 \Omega$ & $15.3 \mathrm{~Hz}$ & $15.2 \mathrm{~Hz}$ \\
\hline $2 \mathbf{m A}$ & $1 \mathrm{~mA}$ & $52 \Omega$ & $30.6 \mathrm{~Hz}$ & $29.3 \mathrm{~Hz}$ \\
\hline $3 \mathrm{~m}$ & $1.5 \mathrm{~mA}$ & $34.7 \Omega$ & $45 \mathrm{~Hz}$ & $42.4 \mathrm{~Hz}$ \\
\hline $4 m$ & $2 \mathrm{~mA}$ & $26 \Omega$ & $60 \mathrm{~Hz}$ & $60 \mathrm{~Hz}$ \\
\hline
\end{tabular}

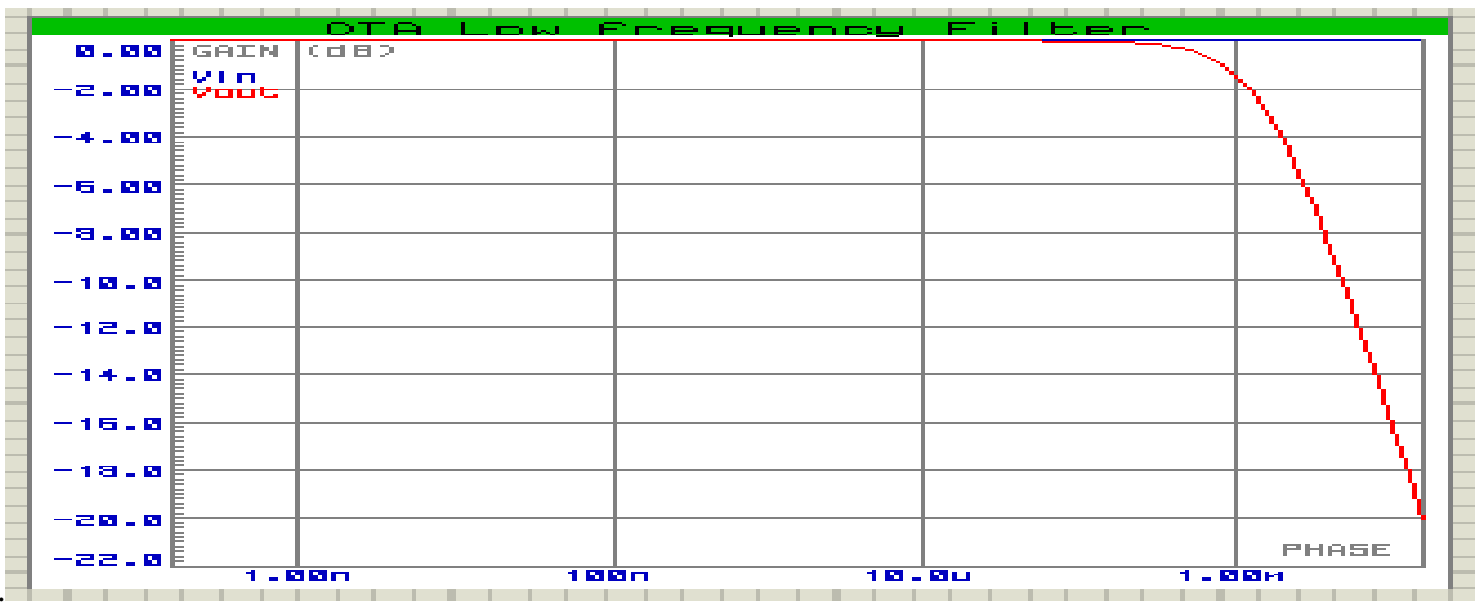


Figure.10 Frequency response of Proteus professional 7.5 simulated OTA-C low pass filter circuit, for $\mathrm{C}=$ $100 \mu \mathrm{F}$ with $\mathrm{I}_{\text {bias }}=100 \mathrm{nA}$, with maximum gain $0 \mathrm{~dB}$ and cut off frequency of $1.52 \mathrm{mHz}$ at $-3 \mathrm{~dB}$

From table 1.4 it is clear that by varying the bias current from $100 \mathrm{nA}$ to $4 \mathrm{~mA}$ that is for each OTA it is from $50 \mathrm{nA}$ to $2 \mathrm{~mA}$ the cut off frequencies obtained are from $1.52 \mathrm{mHz}$ to $60 \mathrm{~Hz}$, for $\mathrm{C}=100 \mu \mathrm{F}$.

As capacitance value $\mathrm{C}$ is further increased, for given bias currents from 50nA to $2 \mathrm{~mA}$, still lower value of cut off frequencies can be obtained. Current division technique used in two OTAs filter structure to obtain lower values of bias current implies very low transconductances. In this paper a low transconductance of order $2 \mu$ siemens for the external bias 100nA for single OTA filter structure and $1 \mu$ siemen of transconductance for the external bias current of 50nA for two OTAs filter structure are obtained.

\section{CONCLUSION}

OTA-C filter realized with minimum number of OTA's and capacitor is an innovative method of designing low frequency active filters which have flexibility in respect of pass band width. The above discussion concludes that we can achieve a tunable range of low frequencies only by changing externally accessible bias current which changes parameter $\mathbf{g}_{\mathbf{m}}$ transconductance of a device. All the requirements such as low supply voltage of order $1.8 \mathrm{~V}$, low component count and portability are achieved.

OTA-C RC filters design using single OTA and two OTAs explain the application of OTA in active filter design of low frequency of order of $3.09 \mathrm{mHz}$ and $1.52 \mathrm{mHz}$ respectively. In these low frequency filters OTA behaves as positive resistance simulator. There is a good agreement between theoretical, and software results and also with the experimental observations. Butterworth characteristics of filter is desirable at such low frequency with out mixing of any noise signals[7]. The filter characteristics are stable at low frequency of $1.52 \mathrm{mHz}$ on wards, and have applications in, biomedical science, sensor circuits and neural networks [8].

\section{ACKNOWLEDGEMENTS}

The author acknowledge the help rendered by VGST by giving level 2 assistance for the precurement of softwares, deviceses and instruments which have been used.

\section{REFERENCES}

[1] Shuenn Yuh Lee, Chih-Jen Cheng, "Systematic Design and Modeling of a OTA-C Filter for Portable ECG Detection" IEEE TRANSACTIONS ON BIOMEDICAL CIRCUITS AND SYSTEMS, VOL. 3, NO. 1, FEBRUARY 2009

[2] Moein Shayegannia ,Hasan Al-Nashash "Low Frequency Filter design Using Gyrator for Biomedical Applications" American University of Sharjah, Sharjah, UAE 00017488@aus.edu and hnashash@aus.edu

[3] Mrs. Ashu Soni, Mr. Sumit Kumar, Ms. Shivani Gupta "OTA Model Used in Active-Passive Filter for Lowering Power Consumption" http: / www.ijesrt.com(C)International Journal of Engineering Sciences \& Research Technology

[4] G. Düzenli, Y. Kılıç, H. Kuntman and A. Ataman: "On the design of low-frequency filters using CMO OTAs operating in the subthreshold region" Microelectronics Journal, Vol.30, No. 1, pp.45-54, 1999.

[5] Abhay Pratap Singh, Sunil Kr. Pandey, Manish Kumar "Operational Transconductance Amplifier for Low Frequency Application” IJCTA | MAY-JUNE 2012

[6] Siva V. Thyagarajan, , Shanthi Pavan, and Prabu Sankar "Active-RC Filters Using the Gm-Assisted OTA-RC Technique” IEEE JOURNAL OF SOLID-STATE CIRCUITS, VOL. 46, NO. 7, JULY 2011

[7] "A Basic Introduction to Filters Active, Passive, and Switched-Capacitor" National Semiconductor Application Note 779 Kerry Lacanette April 1991

[8] Garima1, Priya Banga, Akshita Singh "Active Filter Design Using OTA Realization" www.ijetae.com (ISSN 2250-2459 (Online), Volume 4, Special Issue 1, February 2014) 